\title{
THE STRUCTURAL AND CONSTRUCTION PERFORMANCES OF A LARGE-SPAN HALF STEEL-PLATE-REINFORCED CONCRETE HOLLOW ROOF
}

\author{
Meng-Zhu Diao ${ }^{1,2}$, Yi Li ${ }^{1,}{ }^{*}$, Xin-Zheng Lu ${ }^{3}$, Hong Guan ${ }^{2}$ and Yun-Lun Sun ${ }^{4}$ \\ ${ }^{1}$ College of Architecture and Civil Engineering, Beijing University of Technology, Beijing, China \\ ${ }^{2}$ School of Engineering and Built Environment, Griffith University Gold Coast Campus, Gold Coast, Australia \\ ${ }^{3}$ Department of Civil Engineering, Tsinghua University, Beijing, China \\ ${ }^{4}$ Chinergy Co., Ltd., Beijing, China \\ * (Corresponding author: E-mail: yili@bjut.edu.cn)
}

\section{A B S T RA C T}

This paper proposes a new large span half steel-plate-reinforced concrete (H-SC) hollow roof structure for nuclear power plants. The roof composes of 23 I-shaped H-SC beams. Each H-SC beam consists of a steel plate assembly (a bottom plate, a web plate and a short top plate), which is cast inside an I-shaped reinforced concrete beam. This novel system not only has an equivalently high bearing capacity, stiffness and lower gravity load comparing with conventional RC roof, but also can be conveniently constructed by using the bottom plates as formworks. The numerical simulation was conducted to demonstrate its mechanical capacities and the influence of construction process. Firstly, a finite element (FE) model for the H-SC composes was built and a one-third scaled 12 meters large-span H-SC beam was tested to validate the proposed FE model and analyze the steel-concrete-interface bond-slip. Then, the numerical simulation was conducted to assess the effect of the construction process on the mechanical performance of the entire roof structure, in which the deactivation element and trace element techniques were used to simulate the deformation induced by the construction process. The results show that the deflection induced by the construction process accounts for $87 \%$ of the final deflection.

\section{AR T I C LE H I S T O R Y}

$\begin{array}{ll}\text { Received: } & 9 \text { April } 2017 \\ \text { Revised: } & \text { 8 October } 2017 \\ \text { Accepted: } & \text { 17 December } 2017\end{array}$

\section{K E Y W O R D S}

Half steel plate-reinforced concrete (H-SC) roof;

Numerical simulation;

Experimental test;

Construction process, deactivation

element technique;

Trace element technique

\section{Introduction}

The roofs for nuclear power plants usually have large span to bridge over nuclear islands. Therefore, truss and shell grid structures are commonly used in the large span roofs of the nuclear power plants due to their light self-weight, such as Dayawan and Linnan nuclear power plants. After the Fukushima incident, the safety of nuclear power plants has been much widely concerned. Comparing with the steel structures, steel-plate-reinforced concrete (SC) structures have higher stiffness and better integrity as well as good fire, blast, impact and seismic resistances $[1,2,3,4]$. Such advantages can significantly improve the disaster prevention ability of nuclear power plants. However, the conventional SC structures cannot be directly used as the large span roof due to their heavy self-weight. In this work, a new large span half steel-plate-reinforced concrete (H-SC) hollow roof is proposed and its mechanical performance is analyzed by using the numerical simulation.

The conventional SC structure is composed of a concrete core and steel plates on both sides of the core. Mechanical connectors have been developed for improving the steel-concrete bond, such as the shear connectors $[5,6,7,8,9]$ shown in Fig. 1(a)-(c).

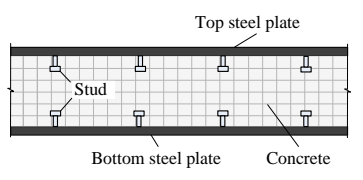

(a) SC with shear studs

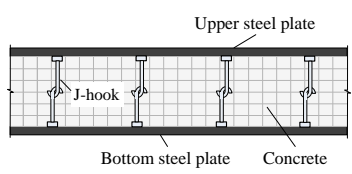

(c) SC with J-hooks

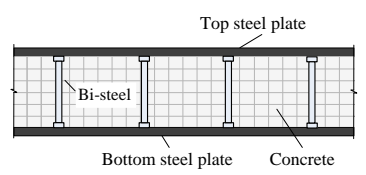

(b) SC with Bi-steels

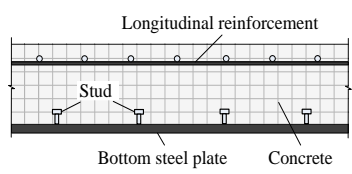

(d) Conventional H-SC
Fig. 1 Typical sections of steel plate reinforced concrete (SC) structures

To facilitate the construction and reduce the internal defects within the concrete, conventional half steel plate-reinforced concrete (H-SC) composites (see Fig. 1(d)) were also introduced in which the top steel plates are replaced by the normal steel reinforcement [5]. The existing experiments on SC and H-SC beam and slab composites indicate that the SC and H-SC composites can significantly reduce the weight when being used on long-span structures, in which steel plates and concrete can work together very well using appropriate shear connections and suitable anchorage length demonstrating a very good level of ductility $[10,11,12,13]$. In addition, the SC and H-SC composites exhibit high capacity and ductility thereby providing adequate protections against earthquake and extreme loads such as impact and blast [14,15]. Specially, comparing with the conventional concrete structures, the need of formworks and exposed concrete crack can be completely eliminated during construction, which significantly shortens construction period and reduces maintenance costs.

The new large span H-SC hollow roof is proposed based on the conventional H-SC structure (see Fig. 2). This roof structure features a bottom steel plate, on top of which a set of vertical steel plates is welded at required spacing as the web plates, and shear studs are installed in between the web steel plates. A short-leg plate is also perpendicularly welded on the top of the web plate. In addition, minimum reinforcement and stirrups are arranged in the beam in accordance with the Chinese code [16]. Each I-shaped assemblage of these steel plates is manufactured on the ground. Subsequently, three or four assemblages are joined by welding and hoisted on the top of shear walls (i.e. the location of the roof). Finally, a total of 23 I-shaped steel assemblages are linked by welding and four lateral steel braces (see Fig. 2(b)) are fitted below the top steel plates. After that, the concrete can be cast on the bottom steel plates. During this stage, the bottom plates perform as formworks while all the steel assemblages provide a large bending capacity to carry construction and gravity loads. These features result in the bottom steel plates in tension and the top steel plates in compression (the compressive buckling being resisted by the lateral steel braces). Note that hollow concrete sections are made around their neutral axis to reduce the self-weight of the whole roof structure. Light-weight materials like aerated concrete blocks can be used as the temporary filler in the hollow sections during the construction process and can be left behind after the construction is completed. All these improvements introduced into the proposed roof facilitate large sectional dimensions to satisfy the requirement of the strength and stiffness of the large-span roofs, with marginally increased self-weight. Moreover, the construction cost can be reduced by using the steel plates as formworks without requiring additional time and materials to build the formworks. All these advantages enable feasible and effective application of the H-SC composites in large-span roofs for nuclear power plant construction. 


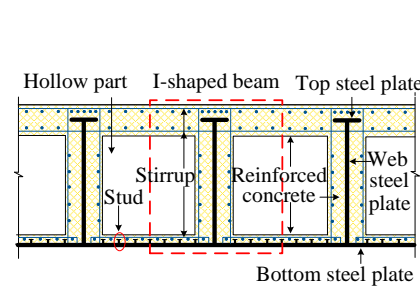

(a) I-shaped part to be tested

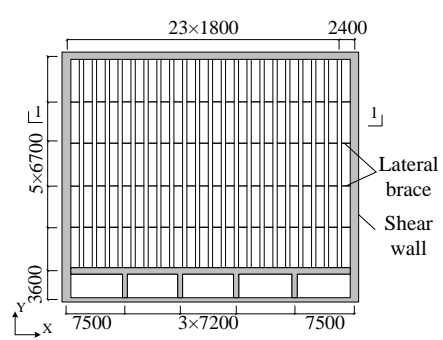

(b) Layout plan

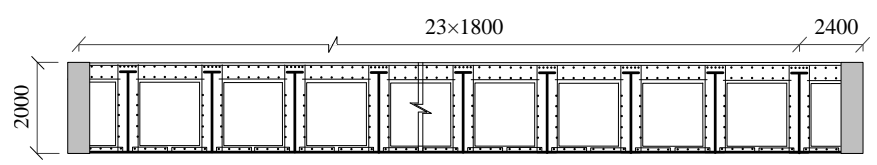

(c) Sectional view

Fig. 2 Proposed H-SC hollow roof structure (unit: $\mathrm{mm}$ )

Current researches on the construction mechanics of SC and $\mathrm{H}-\mathrm{SC}$ composite structures are mainly based on the time varying mechanics theory, in which the construction process is divided into several construction stages. The 'birth' and 'death' element technology is often used in the analysis of the construction process [17]. However, the 'death' element may float after being activated which usually causes the large deviation, resulting in an unconverged solution. The so-called step by step modeling method can also be used for the construction analysis, in which the stress state of each construction step must be reloaded in the consequent construction step as the initial stress state [18]. This results in the large computational workload. Therefore, accurate and efficient construction modeling methods are still needed.

Considering the limitations of the laboratory test on such a large roof specimen, the numerical simulation was used to analyze the mechanical behavior of the proposed H-SC roof structure. Given the structural characteristics of the roof and the construction process, two issues were studied. Firstly, a one-third scaled $12 \mathrm{~m}$ large-span H-SC beam isolated from the roof structure (enveloped by the red-colored rectangle, as shown in Fig. 2(a)) was tested to validate the numerical model for the composite structure, in which the bond slip between the concrete and steel plates was also investigated. Secondly, the whole roof structure was numerically simulated, in which the deactivation element and trace element techniques were used, to evaluate the deformation induced by the construction process.

\section{Experimental test}

To study the mechanical behavior of the proposed H-SC composite and validate the accuracy of the finite element (FE) models, a static test on the one-third scaled $12 \mathrm{~m}$ large-span $\mathrm{H}-\mathrm{SC}$ beam was conducted.

\subsection{Details of the test specimen}

Details of the specimen are shown in Fig. 3(a) and the material properties are given in Table 1. The specimen was $12 \mathrm{~m}$ long, with a clear span of 11.2 $\mathrm{m}$ (see Fig. 3(c)). The cross-sectional area was $600 \mathrm{~mm}$ and $667 \mathrm{~mm}$ in width and depth, respectively. All steel plates used were $8 \mathrm{~mm}$ thick and connected to each other by welding. The bottom steel plate was connected to the concrete through welded studs which served as shear connectors. The specimen was reinforced with 8 diameter bars and the concrete cover was 25 mm. Fig. 3(c) shows the loading arrangement and the test setup. The specimen was placed on the roller bearings to simulate the simply supported boundary condition. A four-point loading system was used: four identical forces were applied to the specimen by two rigid steel beams, on which two equal forces were loaded by two jacks.

\subsection{Construction process}

During the actual construction process of the H-SC roof, the bottom steel plates are used as formworks. Hence, the initial deformation is produced by the dead-weight of the steel plates, which continuously increases with the gravity load of subsequently casted concrete. The deformation reaches a stable stage until the concrete is hardened. Hence, the bearing capacity and stiffness of the roof also increases in stages. As such, the H-SC beam constructed in the real situation is named as multi-step forming (MSF) H-SC beam. However, it is rather challenging to replicate the actual construction process in the laboratory due to the sheer size of the specimen. In the proposed experiment, the specimen

was fabricated on the floor (see Fig. 3(b)), by which no deformation has occurred because the gravity of the steel plates and concrete was directly supported by the floor itself. For this reason, the potential deformation resulted from the actual construction process was not considered in the present test. The test specimen is thus named as one-step forming (OSF) H-SC beam specimen. The test results were used to validate the accuracy of the FE model in the following.

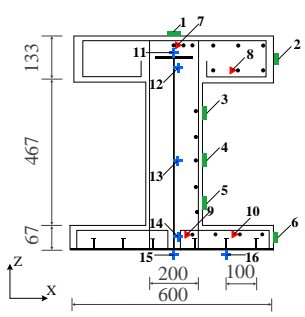

(a) Sectional details

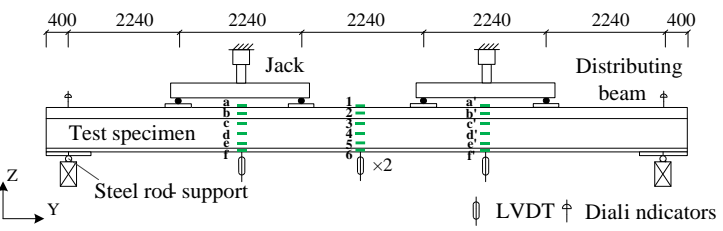

(c) Loading arrangement and instrument layout

Fig. 3 Schematic diagram and fabrication of test (unit: $\mathrm{mm}$ )

Note: = denotes the strain gauges on concrete (No. 1-6 represent the gauges at mid-span, No. a-f and No. a'-f' represent the gauges at $2240 \mathrm{~mm}$ left and right from the mid-span, respectively); denotes the strain gauges on steel bars (No. 7-10); + denotes the strain gauges on steel plates (No. 11-16). Strain gauges are symmetrically arranged with respect to the Z-axis. For clarity, left-hand side strain gauges are not shown in Fig. 3.

Table 1

Material Properties

\begin{tabular}{ccc} 
Material Properties & & \\
\hline \multirow{3}{*}{ Steel bar (HRB335) } & $f_{\mathrm{y}} / \mathrm{MPa}$ & 360 \\
& $f_{\mathrm{u}} / \mathrm{Mpa}$ & 661 \\
& Elongation / $\%$ & 15 \\
\hline \multirow{3}{*}{ Steel plate (Q345B) } & $f_{\mathrm{y}} / \mathrm{MPa}$ & 408 \\
& $f_{\mathrm{u}} / \mathrm{Mpa}$ & 544 \\
& Elongation / $\%$ & 25 \\
\hline \multirow{2}{*}{ Concrete $(\mathrm{C} 35)$} & Cubic compressive strength $f_{\mathrm{cu}}$ & 27 \\
\hline
\end{tabular}

\section{Test results}

\subsection{Overall load-displacement curve}

The load-displacement curve of the specimen is presented in Fig. 4. The specimen underwent the following three stages: (1) elastic stage (OA), (2) elasto-plastic stage (AB), and (3) unloading stage (BC).

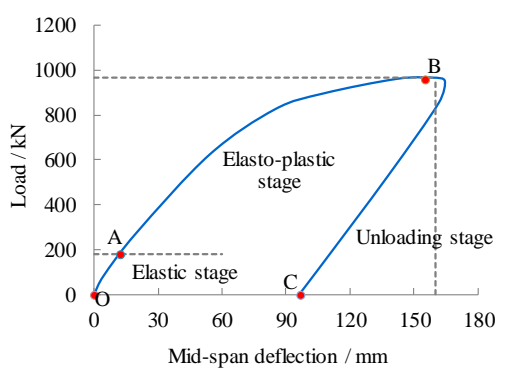

Fig. 4 Load and mid-span displacement relationship

In the elastic stage (OA), all material strains of the specimen at the mid-span section were less than the yield strains of steel and concrete before the mid-span displacement exceeding $12 \mathrm{~mm}$. In the elasto-plastic stage (AB), concrete cracks started to form and gradually developed as the load increased. The load-displacement curve tended to level off (at around Point B) indicating the deterioration of the stiffness of the specimen. In the vicinity of the peak load, the specimen maintained a high capacity (95\% of peak load) within a large range of vertical deformation $(122 \mathrm{~mm}-165 \mathrm{~mm})$, indicating a good level 
of ductility. At this stage, the concrete in the tension zone began to lose its capacity, and subsequently the bottom steel plate and reinforcing steel bars in the tension area started to yield successively. When the load reached the level of $965 \mathrm{kN}$ and the mid-span deflection went up to $165 \mathrm{~mm}$, the bearing capacity of the specimen no longer increased but became stable. Concrete crushing in the compression zone caused failure of the beam, showing a typical flexural failure mode. Following on from this point, the unloading stage (BC) commenced, where the load-displacement curve snapped back until reaching $95 \mathrm{~mm}$ when the unloading stage was terminated.

\subsection{Strain distribution in mid-span steel plate cross-section}

At five load levels, Fig. 5(a) illustrates the strain of the steel plate distributing along the depth of the mid-span section (strain gauges No. 11-15 in Fig. 3(a)), where the Y-axis denotes the section height. It can be seen from Fig. 5(a) that the strains went up gradually as the load increased. The strain distribution remained largely linear when the load was at $100 \mathrm{kN}$. When the load exceeded $200 \mathrm{kN}$, only the central area of web plate satisfied the plane section assumptions. However, both the steel flanges entered into a plastic phase when the load reached $700 \mathrm{kN}$. In addition, the bottom steel plate, having a large cross section, was able to provide a large tensile force. Meanwhile, the ductility increased as the neutral axis moved up steadily during the loading process. Fig. 5(b) presents the strains at three locations of the bottom steel plate, in which the strain at the middle region is greater than those on the left- and right-hand sides, indicating that the tensile stress in the middle is larger due to its connection to the steel web.

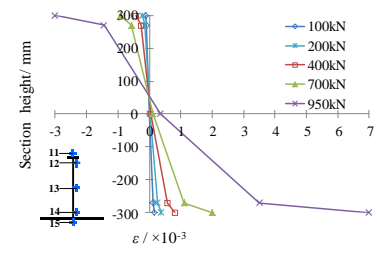

(a) Steel plate

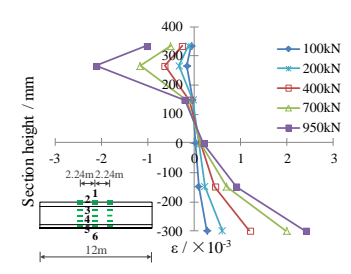

(c) Concrete

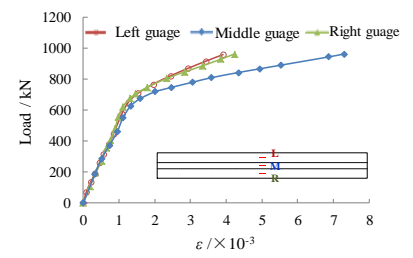

(b) Bottom steel plate

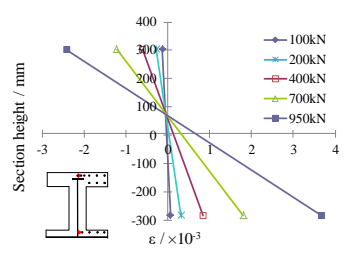

(d) Reinforcement
Fig. 5 Load and mid-span displacement relationship

\subsection{Strain distribution in mid-span concrete cross-section}

At five load levels, Fig. 5(a) illustrates the strain of the steel plate distributing along the depth of the mid-span section (strain gauges No. 11-15 in Fig. 3(a)), where the Y-axis denotes the section height. It can be seen from Fig. 5(a) that the strains went up gradually as the load increased. The strain distribution remained largely linear when the load was at $100 \mathrm{kN}$. When the load exceeded $200 \mathrm{kN}$, only the central area of web plate satisfied the plane section assumptions. However, both the steel flanges entered into a plastic phase when the load reached $700 \mathrm{kN}$. In addition, the bottom steel plate, having a large cross section, was able to provide a large tensile force. Meanwhile, the ductility increased as the neutral axis moved up steadily during the loading process. Fig. 5(b) presents the strains at three locations of the bottom steel plate, in which the strain at the middle region is greater than those on the left- and right-hand sides, indicating that the tensile stress in the middle is larger due to its connection to the steel web.

\subsection{Strain distribution in mid-span reinforcement}

Fig. 5(d) shows the strain development in a top reinforcement ( $Y=304 \mathrm{~mm})$ and a bottom reinforcement ( $\mathrm{Y}=-284 \mathrm{~mm}$ ) as shown in Fig. 3(a) (strain gauge No. 7 and 9). By comparing Fig. 5(a), 5(c) and 5(d), the steel strain was found to be close to the concrete strain at the same height, indicating a modest slip occurred at the concrete and steel interface. Despite this, the strains in concrete and steel bars increased significantly during the entire loading process, suggesting that the shear connectors and stirrups played an effective role in providing adequate confinement. It can be concluded that the steel bars, the concrete, and the steel plate collectively and effectively contributed to the loading process. According to the experimental observation, only a minor shear slip gap had occurred in the bottom steel-concrete interface, which also validated the conclusion above.

\section{Finite element modelling}

\subsection{Geometric modelling}

A 3D model was developed based on the finite element software MSC.MARC [19] in accordance with the actual dimensions of the specimen to analyze the load-deflection behavior and the beam deformation during the construction process (as shown in Fig. 6). The concrete, the steel plates and the steel bars were simulated, respectively, using 8-node solid elements, 4-node thick shell elements and 2-node truss elements. Four identical forces were applied through four rigid blocks to the top flange to avoid stress concentrations and closely replicate the actual situation in the experimental test. The spring elements were used to simulate the bond and slip between the concrete and the steel plate flanges. According to the mechanical characteristics of the specimen, the bond-slip relationship along the span direction was defined whilst those along the other two directions were neglected.

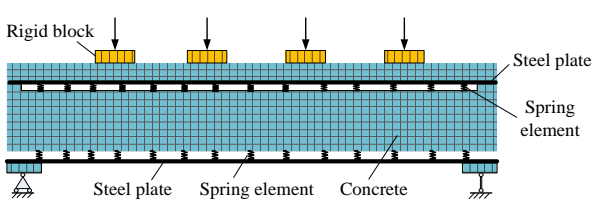

(a) Lateral view

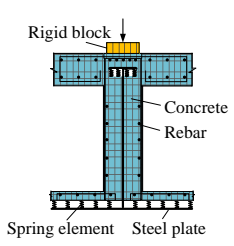

(b) Sectional view
Fig. 6 Finite element model

\subsection{Material model}

The material models recommended by the Chinese code [20] were adopted as shown in Fig. 7. In Fig. 7(c), $f_{\mathrm{u}}$ and $f_{\mathrm{y}}$ are the ultimate and yield strengths of steel, respectively; $\varepsilon_{\mathrm{y}}, \varepsilon_{\mathrm{u}}$ and $\varepsilon_{\mathrm{uy}}$ are the yield and ultimate strains of steel and the strain at the starting point of hardening respectively; and $\mathrm{k}$ is the slope of stress vs. strain during strain-hardening stage. The values of $f_{\mathrm{u}}, f_{\mathrm{y}}$, $\varepsilon_{\mathrm{y}}, \varepsilon_{\mathrm{uy}}, \varepsilon_{\mathrm{u}}$ and $k$ for steel bars are $661 \mathrm{MPa}, 360 \mathrm{MPa}, 0.0019,0.00567,0.0438$ and $7.89 \mathrm{GPa}$, respectively, and those values for steel plates are $544 \mathrm{MPa}, 408$ $\mathrm{MPa}, 0.0022,0.00625,0.0514$ and $3.01 \mathrm{GPa}$, respectively.

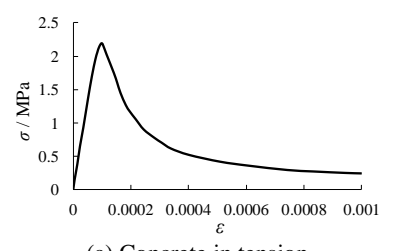

(a) Concrete in tension

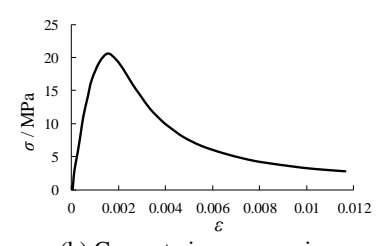

(b) Concrete in compression

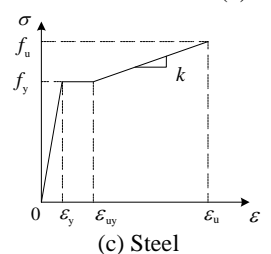

Fig. 7 Material constitutive relationships

\subsection{Shear-slip model}

The analytical model for the shear behavior of the shear stud connectors proposed by Luo [21] was adopted in this study, which is expressed by

$$
\tau=0.026+0.144 s-0.1003 s^{2}+0.0373 s^{3}-0.0056 s^{4}(s \leq 2.35)
$$

$\tau=-0.0053 s+0.1363(2.35 \leq s \leq 10)$

Where $\tau$ is the longitudinal shear stress (MPa) and $s$ is the longitudinal slip (mm). 
Consequently, the shear-slip relationship of the springs simulating the interface between the concrete and the steel plates can be expressed as:

$F(s)=\tau(s) \times A_{i}$

Where $\tau(s)$ is the bond slip constitutive relationship given by (4) and (5), $A_{\mathrm{i}}$ is the area represented by each spring at the interface. Note that the shear forces in the springs are different at different locations, which are marked in Fig. 8 by four distinctive areas. For accurate simulation of the spring properties in the finite element model, four shear-slip relationships were specified for the four affiliated areas.

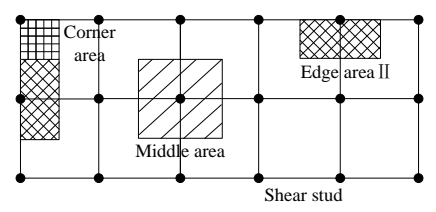

Fig. 8 Affiliated areas of typical springs

\subsection{Experimental validations}

This section compares the results of the models with different bond-slip conditions, namely: (1) without considering the slip between the steel plates and concrete; (2) considering the steel-concrete interface slip. The second condition covered two kinds of slips occurring at the interfaces between: a) only the bottom steel plate and concrete; b) all steel plates (including the bottom, web and top plates) and concrete.

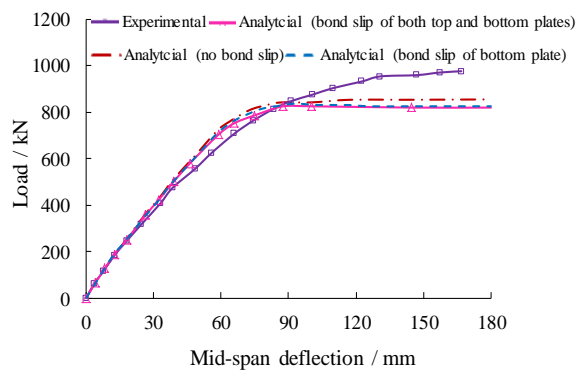

Fig. 9 Comparison between simulation and test

The load-deflection curves under different bond-slip conditions are given in Fig. 9. It can be seen that the numerical and experimental curves are in good agreement. Note that when the deflection exceeded $110 \mathrm{~mm}$, the simulated bearing capacity converged at $855 \mathrm{kN}$. In contrast, the test bearing capacity continuously increased until the load reached $965 \mathrm{kN}$. This is because the horizontal friction forces existing in the actually hinged supports partially restricted the longitudinal deformation of the beam specimen which improved the bearing capacity of the specimen. In addition, the load-deflection curves of the numerical models considering different bond-slip conditions are very close indicating that only a modest slip occurred due to the strong confinement provided by the shear studs. For this reason, the impact of bond slip between the steel plates and concrete can be neglected in the numerical analysis. Therefore, the bond slip between the steel plates and concrete would not be considered in the numerical analysis of the whole H-SC roof structure.

\section{Simulation of construction process}

Since the test of the H-SC beam did not take into consideration of construction process, the numerical analysis of the beam specimen and the whole $\mathrm{H}-\mathrm{SC}$ roof structure was performed in this work to study the influence of the construction process on the deformation development of the MSF H-SC roof structure.

\subsection{Deactivation element technique}

During the construction process of the H-SC roof, welding steel plates, assembling reinforcement and casting concrete were performed in sequence, in which the deformation of the beam increased continuously. Deactivation element technique was used to simulate such a process. The entire model of the roof including the steel plates, rebars and concrete was established first.
Then all elements were deactivated, and consequently the steel plate elements, steel rebar elements and concrete elements were activated in turn to simulate the staged construction process. The strength and stiffness of the elements were ignored when deactivated and were being considered when activated. By doing so, the contributions of different structural components at different construction stages were considered by this technique.

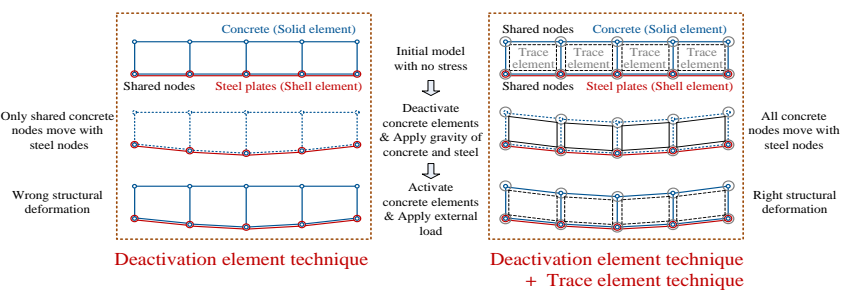

Fig. 10 Simulation of construction process based on the deactivation element and trace element techniques

\subsection{Trace element technique}

A problem still exists in the deactivation element technique: elements were activated only at the initial position where the entire model was built as shown in

Fig. 10. During the actual construction, concrete was cast on the deformed steel plates and consequently hardened with an initial displacement and a low level of stress and strain. This phenomenon cannot be considered by only using the deactivation element technique. Therefore, the trace element technique was also introduced in this study. Trace elements are equivalent to the host structural elements by having the same element mesh and sharing the same nodes with the structural elements but having a very small elastic modulus and mass density. The trace elements for the rebars and concrete deformed together with the structural elements for the steel plates, while the structural elements for the rebars and concrete remained deactivated. As a result, the nodal coordinates of the trace elements were able to provide the correct positions for the subsequent activation of the structural elements for the rebars and concrete, as described in

Fig. 10. Note that the impact of the trace elements on the deformation and stress of the steel plates can be ignored due to its small elastic modulus and mass density.

\subsection{Analysis process}

Deactivation and trace element techniques can be fully implemented using the software MSC.MARC, without resorting to any other program or programming work. The simulation of the construction process includes the following steps:

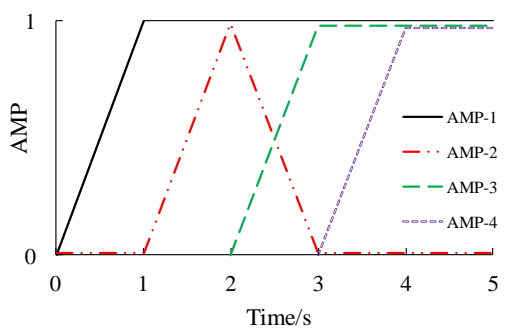

Fig. 11 Relationship of amplitude and time

Deactivation and trace element techniques can be fully implemented using the software MSC.MARC, without resorting to any other program or programming work. The simulation of the construction process includes the following steps:

STEP1: The structural elements (including steel plate, rebar and concrete elements) and trace elements (including the host elements of rebar and concrete elements) were established. Then the structural elements for rebars and concrete were deactivated, and the structural elements for steel plates and the trace elements for rebars and concrete were activated. The gravity load of steel plates was slowly increased in the static analysis (from 0 to $1 \mathrm{~g}$ in 0 to 1 $\mathrm{sec}$, where $\mathrm{g}$ is the gravity acceleration, as shown in Fig. 11) to simulate the equilibrium state of the steel plates under their self-weight. The amplitude-time relationship of the gravity load was named as AMP-1. Note that the time used in the static analysis had no physical meaning and was only 
used for determining the loading stage;

STEP2: The gravity load of concrete and rebars, equivalent to a uniform load, was applied to the bottom steel plate to simulate the gravity load of unhardened reinforced concrete. The amplitude-time relationship of the equivalent uniform load was named as AMP-2;

STEP3: The structural elements for rebars and concrete were activated, and in the meantime their gravity load was gradually increased. The corresponding amplitude-time relationship was named as AMP-3. Simultaneously, the equivalent uniform load in STEP2 decreased gradually. At the end of this step, the equivalent uniform load was completely replaced by the gravity load of concrete and steel. The steel plates, rebars and concrete worked together at this stage;

STEP4: The external load was applied to the beam, which was resisted by the steel plates, rebars and concrete. The corresponding amplitude-time relationship of the external load was named as AMP-4.

\subsection{Simulation results}

\subsubsection{Beam specimen}

Fig. 12(a) compares the load-deflection curves of the MSF and OSF beam models. While the ultimate strengths of the two simulations were different, the trends of the two curves were almost the same. The deformation of the MSF model considering the construction process was equal to that of the OSF model plus the elastic deformation generated during the construction process. In addition, the bearing capacity of the MSF model was about $6 \%$ smaller than that of the OSF model (reduced from $855 \mathrm{kN}$ to $805 \mathrm{kN}$ ) due to the initial deflection of the steel plates. This is because an initial rotational deformation in the cross-sections of the beam was generated by the initial deflection, and this caused a larger elastic-plastic deformation in the steel plates during the loading process.

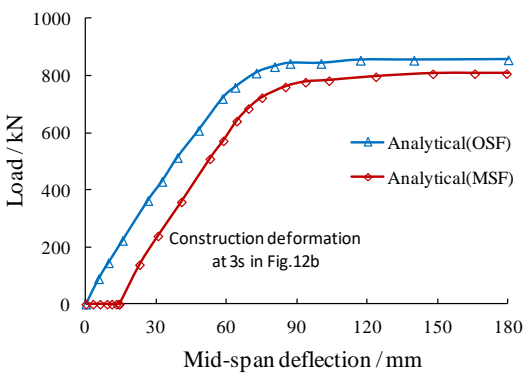

(a) Mid-span deflection of OSF and MSF beam models

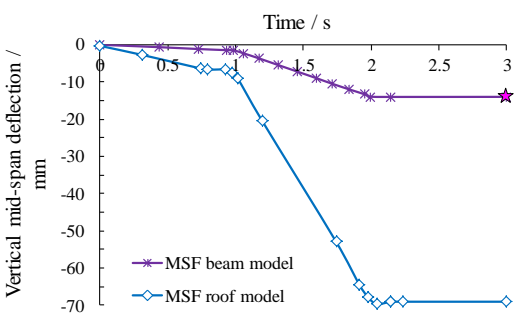

(b) Mid-span deflection development of the beam and roof models during construction process

Fig. 12 Simulated results of beam and roof models

Fig. 12(b) demonstrates the change of the mid-span deflection of the MSF beam against the time during the construction process: (1) from $0 \mathrm{~s}$ to $1 \mathrm{~s}$, a small deformation was found in the steel plates under their self-weight, the maximum deflection was $1.6 \mathrm{~mm}$ at the end of $1 \mathrm{~s}$; (2) from $1 \mathrm{~s}$ to $2 \mathrm{~s}$, the equivalent load of rebars and concrete applied to the bottom steel plate contributed to the further deformation of the steel plates; at the end of $2 \mathrm{~s}$, the mid-span deflection reached the maximum of $13.9 \mathrm{~mm}$; (3) from $2 \mathrm{~s}$ to $3 \mathrm{~s}$, the gravity load of rebars and concrete increased gradually and the equivalent uniform load of rebars and concrete on the bottom decreased gradually, therefore the mid-span deflection of the steel plates remained almost unchanged, successfully achieving the replacement of the equivalent gravity load and the actual self-weight of rebars and concrete.
The numerical model of the proposed roof structure is also built by the same modeling techniques being used for the beam specimen. Considering the snow load, wind load and the gravity load of ancillary equipment pipeline etc. given by the owner and recommended by the regulation [22], the design external load is $30 \%$ of the self-weight of the roof. The develop mode of the deflection of MSF roof model in Fig. 12(b) is similar to that of the beam model indicating the effectiveness of the simulation on the construction process. Fig. 13 demonstrates the stress distribution of concrete and steel plates in the roof model after external loading. The maximum compressive stress of concrete appeared at the bottom of the four side supports due to the effect of the negative bending moment. To be more specific, the stress of the most floor area in the middle part is unidirectional, while the part of the floor close to the corner were under two-way stress, which resulted in a smaller compressive stress in the bottom of the concrete closed to the corner, as seen in Fig. 13(a). It can be seen from Fig. 13(b) that the stress in lower steel plate was relatively smaller due to its large cross section. On the other hand, the middle part contributed in bearing larger compressive stress because of the smaller cross section of the upper steel plate. The deformation and strain of the roof model before concrete casting and after concrete forming are compared in Table 2. The maximum stress of different materials in Table 2 shows that the materials were still in elastic phrase after construction completed, which means the redundancy of the roof structure is very large.

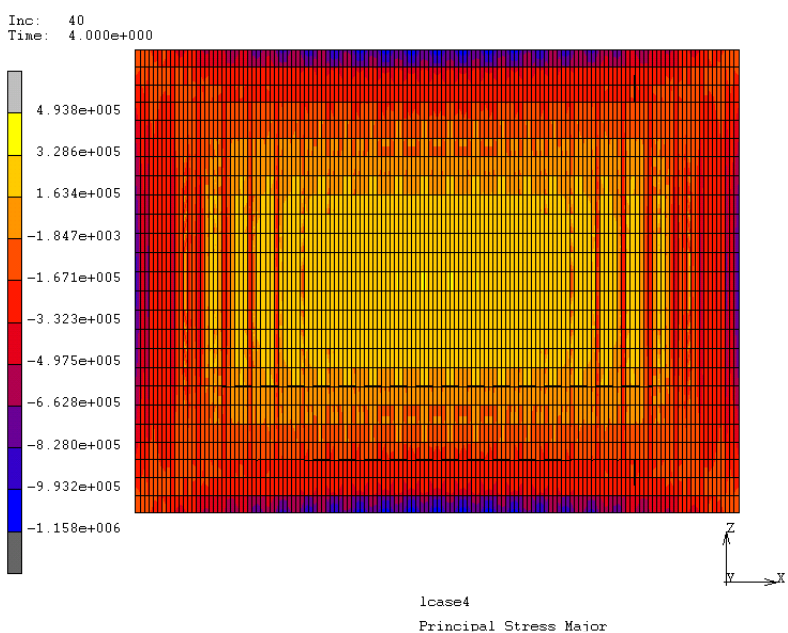

(a) Compressive stress in concrete (From the bottom view)

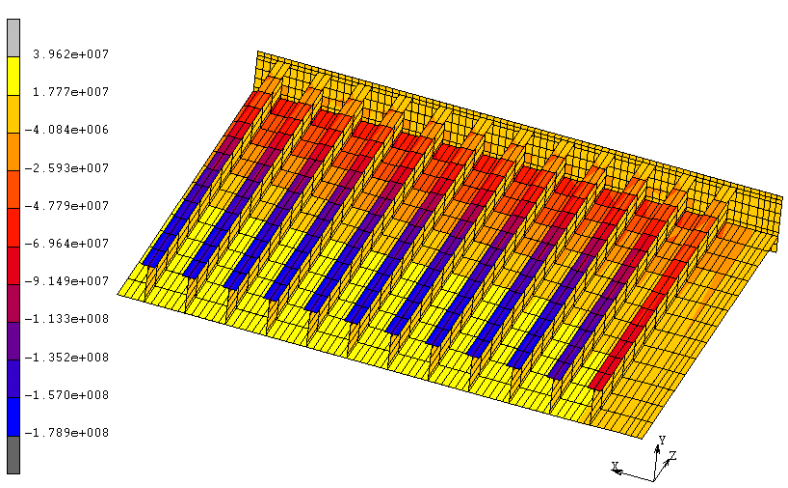

(b) Tensional stress in steel plates (1/4 model)

Fig. 13 Roof model after external loading

Table 2

Mechanical Responses of the H-SC Roof in Different Phrases of Construction Process

\begin{tabular}{cccc}
\hline- & $\begin{array}{c}\text { Before concrete } \\
\text { casting }\end{array}$ & $\begin{array}{c}\text { After concrete } \\
\text { forming }\end{array}$ & $\begin{array}{c}\text { After external } \\
\text { loading }\end{array}$ \\
\hline $\begin{array}{c}\text { Maximum deflection of roof }(\mathrm{mm}) \\
\text { Maximum compressive stress in } \\
\begin{array}{c}\text { concrete (MPa) } \\
\text { Maximum tensional stress in steel } \\
\text { plates (MPa) }\end{array}\end{array}$ & 8 & 69 & 70 \\
$\begin{array}{c}\text { Maximum axial force of lateral } \\
\text { braces }(\mathrm{kN})\end{array}$ & 64 & 0.3 & 1.2 \\
\hline
\end{tabular}


Two key factors are much concerned for the proposed roof. The first one is the deformation of such a large span concrete steel composite roof. The final maximum deflection of the H-SC roof considering the effect of the construction process, i.e., $70 \mathrm{~mm}$, is much smaller than 10/300, i.e., $112 \mathrm{~mm}$, which is the limiting defection value for roof structure (10 is the calculated span of the roof) [20]. The maximum deflection of OSF roof model demonstrating the process without considering the construction influence is only $9 \mathrm{~mm}$, which indicates the deflection induced by the construction process accounts for $87 \%$ of the ultimate deflection.

The second factor is the safety of the roof during the construction process. Before concrete is hardened, the gravity of the roof is only supported by the steel assemblage in which the short upper flange is in compression. The compressive buckling of these flanges will lead to the collapse of the roof. Hence, four lateral steel braces $(2 \mathrm{~L} 160 \times 100 \times 10)$ are connected to the upper flanges by which the compressive buckling of the upper steel flanges is prevented.

According to the Chinese code [23], the axial strength of lateral braces considering buckling $N$ can be calculated by the following equation:

$\frac{N}{\varphi \mathrm{A}} \leq f$

Where $N$ is axial compression force, $A$ is the net sectional area, $f$ is the design value of compressive strength of steel, $\varphi$ is the stability factor of the axially loaded compressive member. The calculated axial strength of the lateral braces is $1820 \mathrm{kN}$, which is significantly larger than the axial forces in the braces during the construction process, i.e., $48.9 \mathrm{kN}$ (as seen in Table 2), indicating that the lateral braces will not be buckled. Both two factors confirm that the proposed roof is safe during the construction process and under the service state.

\section{Carrying capacity and stiffness calculation}

\subsection{Deactivation element technique}

To validate the carrying capacity of $\mathrm{H}-\mathrm{SC}$ beam, an analysis was carried out in terms of the strain diagram shown in Fig. 14 and the calculation was based on the following assumptions: 1) strain of section remains plane; 2) tensile strength of concrete is disregarded; 3) the distribution of concrete stress is simplified to an equivalent rectangular, the depth of equivalent rectangular stress block equals to the depth of neutral axis multiplied by a factor 0.8 ; 4) the actual distribution of steel web stress is trapezoid which is also replaced by an equivalent rectangular in calculation; 5) the stress contribution of longitudinal reinforcement in flanges shall be considered and that in steel web shall be neglected.

Based on the above assumptions, the ultimate flexural strength of H-SC beam can be calculated by means of a simplified plastic method, the formulas are as follows:

$$
\begin{aligned}
& M \leq f_{\mathrm{c}} b h_{\mathrm{t}}\left(h_{0}-\frac{h_{\mathrm{t}}}{2}\right)+f_{\mathrm{c}} b_{0}\left(0.8 x-h_{\mathrm{t}}\right)\left(h_{0}-0.4 x-\frac{h_{\mathrm{t}}}{2}\right)+f_{\mathrm{y}}^{\prime} A_{\mathrm{s}}^{\prime}\left(h_{0}-a_{\mathrm{s}}^{\prime}\right) \\
& +f_{\mathrm{a}}^{\prime} A_{\mathrm{af}}^{\prime}\left(h_{0}-a_{\mathrm{a}}^{\prime}\right)+M_{\mathrm{aw}}
\end{aligned}
$$

$$
f_{\mathrm{c}} b h_{\mathrm{t}}+f_{\mathrm{c}} b_{0}\left(x-h_{\mathrm{t}}\right)+f_{\mathrm{y}}^{\prime} A_{\mathrm{s}}^{\prime}+f_{\mathrm{a}}^{\prime} A_{\mathrm{af}}^{\prime}-f_{\mathrm{y}} A_{\mathrm{s}}-f_{\mathrm{a}} A_{\mathrm{af}}+N_{\mathrm{aw}}=0
$$

The notations used in the above equations are given as follows: $f_{\mathrm{c}}$ is the design value of concrete compressive strength; $b$ is the width of concrete flange; $b_{0}$ is the width of concrete web; $h_{0}$ is the effective depth of section; $x$ is the depth to neutral axis of section; $h_{\mathrm{t}}$ is the depth of flange in compressive zone; $h_{\mathrm{b}}$ is the depth of flange in tension zone; $f_{\mathrm{y}}$ and $f_{\mathrm{y}}^{\prime}$ are the design values for tensile and compressive strengths of steel bars, respectively; $f_{\mathrm{a}}$ and $f_{\mathrm{a}}^{\prime}$ are the design values for tensile and compressive strengths of steel plates, respectively; $A_{\mathrm{s}}$ and $A_{\mathrm{s}}^{\prime}$ are the sectional areas of longitudinal steel bars in tension and compressive zones, respectively; $A_{\mathrm{af}}$ and $A_{\mathrm{af}}^{\prime}$ are the sectional areas of steel plates in tension and compressive zones, respectively; $a_{\mathrm{s}}^{\prime}$ is the distance from the point for resultant of forces of longitudinal steel bars to extreme fiber of section in compression zone; $a_{\mathrm{a}}^{\prime}$ is the distance from the point for resultant of forces of steel plate to extreme fiber of section in compression zone; $M_{\text {aw }}$ is the moment for the axis force of steel plate web to the point of longitudinal tension steel reinforcements and steel plate; $N_{\text {aw }}$ is the axis force of steel plate web. In which, the calculation of $M_{\text {aw }}$ and $N_{\text {aw }}$ are completely followed the formulas in the code [16].

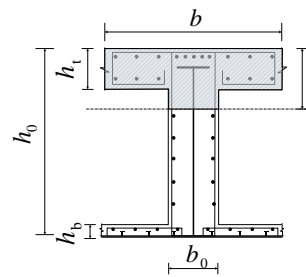

(a) Beam section

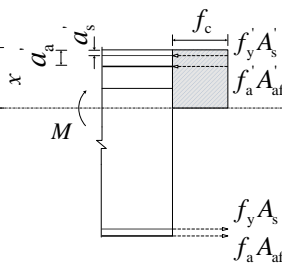

(b) Equivalent stress distributions

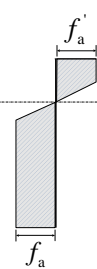

(c) Stress distributions of web plate
Fig. 14 Diagrammatic sketch of calculation

Theoretical values of ultimate load-bearing capacity can be obtained according to

$$
M \leq f_{\mathrm{c}} b h_{\mathrm{t}}\left(h_{0}-\frac{h_{\mathrm{t}}}{2}\right)+f_{\mathrm{c}} b_{0}\left(0.8 x-h_{\mathrm{t}}\right)\left(h_{0}-0.4 x-\frac{h_{\mathrm{t}}}{2}\right)+f_{\mathrm{y}}^{\prime} A_{\mathrm{s}}^{\prime}\left(h_{0}-a_{\mathrm{s}}^{\prime}\right)
$$$$
+f_{\mathrm{a}}^{\prime} A_{\mathrm{af}}^{\prime}\left(h_{0}-a_{\mathrm{a}}^{\prime}\right)+M_{\mathrm{aw}}
$$

And

$$
f_{\mathrm{c}} b h_{\mathrm{t}}+f_{\mathrm{c}} b_{0}\left(x-h_{\mathrm{t}}\right)+f_{\mathrm{y}}^{\prime} A_{\mathrm{s}}^{\prime}+f_{\mathrm{a}}^{\prime} A_{\mathrm{af}}^{\prime}-f_{\mathrm{y}} A_{\mathrm{s}}-f_{\mathrm{a}} A_{\mathrm{af}}+N_{\mathrm{aw}}=0
$$

It is $7.7 \%$ greater than the test value, as shown in Table 3. Considering that the theoretical method does not take into account the intensification of steel bars and steel plate, so a relatively conservative flexural strength can be obtained using this method.

Table 3

Comparison between the experimental and theoretical strength and stiffness results

\begin{tabular}{cccc}
\hline & $\begin{array}{c}\text { Experimental } \\
\text { results }\end{array}$ & Theoretical values & Relative error \\
\hline Flexural capacity $(\mathrm{kN} \cdot \mathrm{m})$ & 1694 & 1563 & $7.7 \%$ \\
Short-term stiffness $\left(\mathrm{kN} \cdot \mathrm{m}^{2}\right)$ & $2.22 \times 10^{5}$ & $2.12 \times 10^{5}$ & $4.5 \%$ \\
\hline
\end{tabular}

\subsection{Stiffness validation}

The theoretical and experimental stiffness values are listed in Table 3 . According to the code [16], the short-term theoretical stiffness $B_{\mathrm{s}}$ can be calculated by the following equation:

$B_{\mathrm{s}}=\left(0.2210^{-3}+3.75 \frac{E_{\mathrm{s}}}{E_{\mathrm{c}}} \rho_{\mathrm{s}}\right) E_{\mathrm{c}} I_{\mathrm{c}}+E_{\mathrm{a}} I_{\mathrm{a}}$

Where $E_{\mathrm{s}}, E_{\mathrm{c}}, E_{\mathrm{a}}$ represents modulus elasticity of steel bar, concrete, steel plate respectively. $\rho_{\mathrm{s}}$ is the reinforcement ratio of longitudinal tensile steel bar. $I_{\mathrm{c}}$ is the moment of inertia of concrete section, $I_{\mathrm{a}}$ is the moment of inertia of steel section.

The short-term experimental stiffness $B_{\text {st }}\left(\boldsymbol{B}_{\mathrm{st}}=\boldsymbol{E} \boldsymbol{I}=0.01575 \mathrm{Pl}^{3} / \Delta\right.$ (11)) can be derived from the structural mechanics formula ( $\Delta=\int \frac{M \bar{M}}{E \boldsymbol{I}} \boldsymbol{A}(10)$ ), which reflects the relationship between stiffness, applied load and deflection in linear phase.

$\Delta=\int \frac{M \bar{M}}{E I} d l$

$B_{\mathrm{st}}=E I=0.01575 P l^{3} / \Delta$

Where $M$ is the internal moment due to loads acting on the specimen, $\bar{M}$ is the internal moment caused by an assumed unit load $P=1, E I$ is the flexural rigidity of a cross section, $\Delta$ is the test displacement, $B_{\mathrm{st}}$ is the testing values of the bending stiffness, $P$ is the applied load, $l$ is the specimen span.

Theoretical values of the bending stiffness in the linear phrase can be obtained by bring the inflection point values $(80.9 \mathrm{~mm}, 810.3 \mathrm{kN})$ into Eq. 9 . It can be seen from Table 3 that the stiffness of the beam bending theoretical values are in good agreement with the test values. 


\section{Conclusions}

In this study, the mechanical behavior and construction process of a large-span H-SC roof system were studied. A large scaled beam was tested and the numerical simulations of the beam specimen and whole roof structure were carried out to investigate the mechanisms of the H-SC roof and the impact of the construction process on the $\mathrm{H}-\mathrm{SC}$ roof structure. The main findings are summarized below:

(1) Under ultimate load, concrete crushing occurred in compression and yielding of the steel plate and tension reinforcement was found in the $\mathrm{H}-\mathrm{SC}$ composite beam, showing a typical flexural failure mode. Minor slippage occurred between the steel plates and concrete in the bottom flange until the load exceeded $700 \mathrm{kN}$, and no debonding failure was observed. It can be concluded that with appropriate shear connections, the steel plates and concrete were able to effectively work together in full composite action.

(2) The comparison between the experimental and numerical results revealed that the finite element model developed in this study was capable of accurately reproducing the mechanical characteristics of the H-SC roof. In addition, the bond slip was found to be small due to the adequately anchored shear connections.

(3) The deactivation element technique and trace element technique were used to simulate the construction process of the H-SC roof. The numerical results indicated that the two techniques can simulate the development of deformation in the process of construction. The deflection induced by the construction process accounts for $87 \%$ of the ultimate deflection.

(4) The numerical simulation shows that the proposed H-SC composite roof has enough bearing capacity and stiffness to meet the requirement for the large span structure. And the lateral braces can effectively prevent the compressive buckling of the steel plate assemblage during the construction process. In addition, the comparison between the theoretical and experimental results confirms that the proposed method could accurately calculate the ultimate flexural strength and stiffness of $\mathrm{H}-\mathrm{SC}$ beam and provides a reference for the design of H-SC structures.

\section{Acknowledgements}

This work was financially supported by the National Key Research and Development Program of China (No. 2016YFC0701400), the National Natural Science Foundation of China (No. 51578018), Beijing Nova Program (No. xx2017093) and the International Research Cooperation Seed Fund of Beijing University of Technology (No. A04).

\section{References}

[1] Ma K.J., Xiao J.C., Zhang H.A., Zhang H.P., Zhang Ha., Qi X. and Bai F.J., "A new type of steel-concrete composite plate", Proceedings of 6th Pacific Structural Steel Conference, Beijing, China, 1070-1075, 2001

[2] Teng J.G., Wong H.T., Wang Z.C. and Dong S.L., "Steel-concrete composite shell roofs: structural concept and feasibility. Advances in Structural Engineering", 8(3), 287-308, 2005.

[3] Shanmugam N.E. and Lakshmi B., "State of the art report on steel-concrete composite columns", Journal of Constructional Steel Research, 57(10), 1041-1080, 2001.

[4] Andrews A. and Folger P., "Nuclear power plant design and seismic safety considerations", Congressional Research Service Report, Report R41694, Washington D.C., USA, 2012.

[5] JEAC 4618-2009, Technical Code for Seismic Design of Steel Plate Reinforced Concrete Structures: Buildings and Structures, Japanese Electric Association Nuclear Standards Committee (JEAC), Tokyo, Japan, 2009.

[6] Bowerman H., Coyle N. and Chapman J.C., "An innovative steel/concrete construction system", The Structural Engineering, 80(20), 33-38, 2002.

[7] Liew J.Y.R. and Sohel K.M.A., "Lightweight steel concrete-steel sandwich system with J-hook connector", Engineering Structure, 31(5),1166-1178, 2009

[8] Liew J.Y.R. and Sohel K.M.A., "Structural performance of steel-concrete-steel sandwich composite structures", Advances in Structural Engineering, 13(3), 453-470, 2010.

[9] Liu J.B., Liew J.Y.R. and Zhang M.H., "Shear-tension interaction strength of J-hook connectors in steel-concrete-steel sandwich structure", Advanced Steel Construction, 11(1), 73-94, 2015.

[10] Oduyemi T.O.S. and Wright H.D., "An experimental investigation into the behavior of double-skin sandwich beams", Journal of Constructional Steel Research, 14, 197-220, 1989.

[11] Nie J.G. and Zhao J., "Flexural behavior of steel plate-concrete composite beams", Key Engineering Materials, 400-402, 37-42, 2009

[12] Li G.Q. Liang L and Li X.H. "Experimental and theoretical study on the behavior of the steel-concrete composite beam with notched web of inverted T-shaped steel section at construction stage", Advanced Steel Construction, 7(4), 376-386, 2011.

[13] Li G.Q., Liang L. and Li X.H., "Experimental study on behaviors of the trapezoid connectors of the inverted T-shaped steel with notched web for a novel composite beam",
Advanced Steel Construction, 7(1), 48-63, 2014.

[14] Liew J.Y.R. and Wang T.Y., "Novel steel-concrete-steel sandwich composite plates subject to impact and blast load", Advances in Structural Engineering, 14(4), 673-687, 2011.

[15] Kong S.Y., Remennikov A.M. and Uy B., "An experimental investigation of the performance of non-composite steel-concrete-steel protective panels under large impact loading", Advances in Structural Engineering, 16(7), 1163-1174, 2013.

[16] JGJ 138-2001, Technical specification for steel reinforced concrete composite structures, The Ministry of Housing and Urban-Rural Development of the People's Republic of China (MOHURD), Beijing, China, 2001.

[17] Fang S.W. and Yuan X.F., "Construction analysis of the chimney of solar thermal power station", Applied Mechanics and Materials, 283, 41-46, 2013.

[18] Zhang Q.L., Luo X.Q., Gao Z.F., and Li Z.X., "Numerical tracing and graphic simulation for construction processes of large span pre-tensioned steel structure", Journal of Tongji University, 32(10), 1295-1299, 2004.

[19] MSC. Marc 2007, "User documentation volume A: Theory and user information", MSC. Software Corporation, www.mscsoftware.com, 2007.

[20] GB50010-2010, Code for Design of Concrete Structures, The Ministry of Housing and Urban-Rural Development of the People's Republic of China (MOHURD), Beijing, China, 2010.

[21] Luo H.X., "Longitudinal shear resistant problem about the steel deck-concrete composite slabs", Ph.D. Thesis, Chongqing University, Chongqing, China, 2004.

[22] GB50009-2012, Load Code for the Design of Building Structures, The Ministry of Housing and Urban-Rural Development of the People's Republic of China (MOHURD), Beijing, China, 2012.

[23] GB50017-2003, Code for Design of Steel Structures, The Ministry of Housing and Urban-Rural Development of the People's Republic of China (MOHURD), Beijing, China, 2003. 